\title{
The caspase-9 derived C-terminal fragment of cytokeratin 18 modulates topoisomerase action
}

\author{
B. SCHUTTE ${ }^{1}$, M.E.R. HENFLING ${ }^{1}$, F.K.C.P. VERHEYEN ${ }^{1}$, G. LI $^{2}$, \\ G.V. TOLSTONOG ${ }^{2}$ and F.C.S. RAMAEKERS ${ }^{1}$

\begin{abstract}
${ }^{1}$ Department of Molecular Cell Biology, GROW - School for Oncology and Developmental Biology, Maastricht University Medical Center, P.O. Box 616, 6200 MD Maastricht, The Netherlands;

${ }^{2}$ Max-Planck-Institut für Zellbiologie, Rosenhof, D-68526 Ladenburg, Germany
\end{abstract}

Received March 12, 2009; Accepted April 21, 2009

DOI: 10.3892/ijo_00000374

\begin{abstract}
During early apoptosis the 33 amino acid C-terminal cytokeratin 18 (CK18) fragment is released by caspase-9 cleavage at the ${ }^{393} \mathrm{DALD} / \mathrm{S}$ site. This basic peptide relocates from the cytoskeleton to the nucleoplasm as shown by confocal laser scanning. It is shown that the $\mathrm{C}$-terminal peptide modulates topoisomerase activity as measured by relaxation of plasmid DNA. In an in vitro assay recombinant caspase-induced chromatin condensation is inhibited by the peptide and at the electron microscopical level a clear inhibition of nucleolar breakdown was observed in its presence. We hypothesize that the C-terminal CK18 fragment exerts an effect in the nucleolus by stimulating rRNA transcription and processing via modulation of enzymatic activity of topoisomerase I. This leads to preservation of general transcriptional activity required to exert active steps during early stages of programmed cell death.
\end{abstract}

\section{Introduction}

Characteristic for apoptosis is the cessation of many cellular processes, the breakdown of intracellular organelles including the cytoskeleton and the collapse of the nucleus. The orchestrated cellular breakdown is mediated by caspases, which target crucial proteins within the cell (1). Among the different caspase substrates are the intermediate filaments (2-7), including the cytokeratins and the nuclear lamins $(8,9)$. Limited proteolysis of these targets results in a rapid collapse of the cytoskeleton and loss of cell-cell or cell-matrix interactions.

Correspondence to: B. Schutte, Department of Molecular Cell Biology (Box 17), University of Maastricht, P.O. Box 616, 6200 MD Maastricht, The Netherlands

E-mail: bert.schutte@molcelb.unimaas.nl

Key words: cytokeratin 18, caspase cleavage, apoptosis, M30 CytoDeath, chromatin condensation, nucleolus, topoisomerase I, C-terminal peptide
Cleavage of a target results not only in impairment of its function, but simultaneously leads to the production of cleavage fragments, which may have a specific function. For instance, cleavage of c-IAP results in the liberation of a proapoptotic C-terminal fragment (10).

Cytokeratin 18 (CK18) contains a caspase consensus site in the conserved L1-2 linker region of the central $\alpha$-helical rod domain, which is targeted by caspase- 6 . A second caspase cleavage site was identified in the $\mathrm{C}$-terminal (tail) domain of CK18, which is targeted in vitro by caspase-3, -7 and -9 (6). This C-terminal caspase cleavage of CK18 is an early event during apoptosis and precedes DNA fragmentation and loss of membrane phospholipid asymmetry. It occurs immediately after the mitochondria loose their membrane potential and release cytochrome c into the cytoplasm. Cleavage of CK18 at the C-terminus does not affect the cytokeratin cytoskeleton organization to a great extent, since cells still show a normal filamentous structure and remain attached to their substrate (3). The second cleavage event at the L1-2 linker region results in the collapse of the cytokeratin network.

The fact that the caspase-9 C-terminal cleavage fragment of CK 18 has basic properties and that basic cleavage products of the intermediate filament protein vimentin can affect nuclear organization (11), led us to examine the potential role of the liberated C-terminal CK18 peptide in chromatin organization during early apoptosis. Here we show that the C-terminal caspase cleavage product of cytokeratin 18 is able to interfere with topoisomerase I-mediated chromatin condensation during apoptosis.

\section{Materials and methods}

Cell cultures. The human non-small cell lung cancer cell line MR65 was cultured as a monolayer in Eagle's modified minimal essential medium (EMEM) (Gibco, Invitrogen, Breda, The Netherlands) supplemented with $10 \mathrm{mM}$ Hepes (Gibco), $1 \%$ (v/v) non-essential amino acids (Gibco), 2 mM L-glutamine (Serva, Heidelberg, Germany), $50 \mu \mathrm{g} / \mathrm{ml}$ gentamycin (AUV, Cuijk, The Netherlands) and 10\% (v/v) heat-inactivated newborn calf serum (Gibco). Cells were maintained in a humidified incubator at $37^{\circ} \mathrm{C}$ and $5 \% \mathrm{CO}_{2}$ 
and harvested by trypsinization. HeLa cells were cultured in EMEM supplemented with $10 \mathrm{mM}$ Hepes, $1 \%$ (v/v) nonessential amino acids, $2 \mathrm{mM}$ L-glutamine, $50 \mu \mathrm{g} / \mathrm{ml}$ gentamycin and $10 \%(\mathrm{v} / \mathrm{v})$ heat-inactivated fetal calf serum.

Jurkat cells (T-cell lymphoma), which grow in suspension, were cultured in RPMI-1640 medium without L-glutamine, supplemented with $0.1 \%$ gentamycin, $1 \%$ L-glutamine and $10 \%$ heat-inactivated newborn calf serum.

Induction of apoptosis. Apoptosis was induced by incubation of cell cultures with the cyclin-dependent kinase (CDK) inhibitor roscovitine, a kind gift of Dr L. Meijer (Station Biologique, CNRS, Roscoff, France), Stock solutions were prepared in dimethylsulfoxide (DMSO). Roscovitine was added to the cultures in a final concentration of $50 \mu \mathrm{M}$ for the indicated time periods.

\section{Materials}

Recombinant caspases. Recombinant caspase-3 was a kind gift from Dr G. Salvesen (Burnham Institute, San Diego, USA). Recombinant caspase-9 was purchased from BioVision Inc., Mountain View, CA. Recombinant caspases were stored in working buffer (20 mM Hepes, $100 \mathrm{mM} \mathrm{NaCl}, 0.1 \%$ CHAPS, $10 \mathrm{mM}$ dithiothreitol (DTT), $1 \mathrm{mM}$ EDTA and $\mathrm{pH}$ 7.4) at $-70^{\circ} \mathrm{C}$. For in vitro studies recombinant caspases were used in a final concentration of $0.8 \mu \mathrm{g} / \mathrm{ml}$ for caspase-3, $-6,-7$ and -8; for caspase-9 1 unit was used.

Caspase inhibitor. Caspase-6 inhibitor (z-VEID-fmk) was obtained from Alexis (Kordia, Leiden, The Netherlands). The caspase inhibitor was dissolved in DMSO and used in a final concentration of $100 \mu \mathrm{M}$.

C-terminal CK18 peptide. The 33-mer C-terminal CK18 fragment SSNS MQTIQKTTTR RIVDGKVVSE TNDTK VLRH (10 mg) was synthesized by Pepscan Systems B.V. (Lelystad, The Netherlands). The peptide was dissolved in $\mathrm{H}_{2} \mathrm{O}$ and stored as a stock of $5 \mathrm{mg} / \mathrm{ml}$ at $-20^{\circ} \mathrm{C}$.

Antibodies. Polyclonal rabbit antiserum CA1, raised against the C-terminal peptide of CK18 was kindly provided by E.B. Lane (3). As secondary antibody fluorescein isothiocyanate (FITC)-conjugated goat anti-rabbit IgG [Southern Biotechnology Associates (SBA), Birmingham USA; diluted $1: 80]$ was used.

Immunocytochemistry and confocal scannning light microscopy was performed as described previously (3). The primary antibody M30 (diluted 1:40) was obtained from Peviva AB (Bromma, Sweden).

Electrophoretic mobility shift assay (EMSA). EMSA was performed according to Li et al (12). Portions of $0.2 \mu \mathrm{g}$ of negatively supercoiled plasmid pDesB25 (mouse $\gamma$-satellite centromeric repeat, Genbank acc. no. AJ403322) were incubated for $60 \mathrm{~min}$ at $37^{\circ} \mathrm{C}$ in $20 \mu \mathrm{l}$ of binding buffer [30 mM triethanolamine (TEA), $\mathrm{pH} 7.0$ and 5\% glycerol] supplemented with increasing quantities of C-terminal CK18 peptide (0-125 ng). The reaction mixtures were supplemented with 0.2 vol of gel-loading buffer ( $5 \mathrm{x}$ : $40 \mathrm{mM}$ Tris- $\mathrm{HCl}$, $\mathrm{pH} 6.8,10 \%$ glycerol and $0.025 \%$ bromophenol blue) and subjected to electrophoresis on 1\% Seakem GTG agarose gel (Biozym, Hess. Oldendorf, Germany) in 0.5X TBE buffer in an electric field of $5 \mathrm{~V} / \mathrm{cm}$ for $\sim 4 \mathrm{~h}$ at room temperature. The gels were treated with ethidium bromide and the DNA was visualized under UV light.

Calf thymus topoisomerase I relaxation assay. Topoisomerase I relaxation assay was perfomed according to Li et al (12). Quantities of $0.2 \mu \mathrm{g}$ of negatively supercoiled pDesB25 DNA were incubated with 2 units of calf thymus topoisomerase I (MBI Fermentas, St. Leon-Rot, Germany) in $50 \mu 1$ of reaction buffer (10 mM Tris-HCl, pH 8.0, $150 \mathrm{mM} \mathrm{NaCl}, 5 \mathrm{mM}$ $\mathrm{MgCl}_{2}, 5 \mathrm{mM}$ DTT, $1 \mathrm{mM}$ EDTA and $2 \mathrm{mM}$ spermidine) in the presence of increasing amounts of C-terminal CK18 peptide $(0-5 \mu \mathrm{g})$ for $1.5 \mathrm{~h}$ at $37^{\circ} \mathrm{C}$. The reactions were terminated by the addition of an equal volume of stop buffer $(0.2 \mathrm{mg} / \mathrm{ml}$ of proteinase $\mathrm{K}$ in $2 \%$ SDS and $50 \mathrm{mM}$ EDTA), followed by incubation at $37^{\circ} \mathrm{C}$ for $2 \mathrm{~h}$. The DNA samples were purified by phenol/chloroform extraction, concentrated by ethanol precipitation, and subjected to electrophoresis on $1 \%$ SeaKem GTG agarose gels in $0.5 \mathrm{X}$ TBE buffer in an electric field of $5 \mathrm{~V} / \mathrm{cm}$ for $\sim 4 \mathrm{~h}$ at room temperature. The gels were treated with ethidium bromide and the DNA was visualized under UV light.

Preparation of nuclei. Nuclei were prepared according to a modification of the method described by Ruchaud et al (9). Briefly, Jurkat cells (four $75 \mathrm{~cm}^{2}$ culture flasks) were rinsed in ice-cold PBS and centrifuged at $200 \mathrm{x} \mathrm{g}$. The pellet was resuspended in a $15 \mathrm{ml}$ conical centrifuge tube with $10 \mathrm{ml}$ of hypotonic extraction buffer (HEB) containing $50 \mathrm{mM}$ PIPES, $\mathrm{pH}$ 7.4, $50 \mathrm{mM} \mathrm{KCl}, 5 \mathrm{mM}$ EGTA, $2 \mathrm{mM} \mathrm{MgCl}_{2}, 1 \mathrm{mM}$ dithiothreitol (DTT) and $0.1 \mathrm{mM}$ phenylmethylsulfonyl fluoride (PMSF). The cells were centrifuged at $1000 \mathrm{x} g$ to form a tight pellet, and the volume of the cell pellet was approximated. The supernatant was aspirated and HEB was added to a volume between 0.5 and $1 \mathrm{x}$ the pellet volume. The cells were transferred to a $2 \mathrm{ml}$ Dounce homogenizer and allowed to swell for 20-30 min on ice. Cells were lysed with 10 gentle strokes of a B-type teflon pestle $(600 \mathrm{rpm})$. The desired extent of cell lysis $(>90 \%)$ was monitored under the microscope by propidium iodide (PI, Calbiochem) staining.

Caspase treatment of nuclei. The effect of C-terminal CK18 peptide on caspase-induced nuclear changes was studied by adding $1 \mu \mathrm{l}$ caspase-3 (final concentration $0.8 \mu \mathrm{g} / \mathrm{ml}$ ) to $20 \mu \mathrm{l}$ cell nuclei in the presence or absence of the peptide. Four microlitres C-terminal CK18 peptide $(5 \mathrm{mg} / \mathrm{ml})$ was added to $20 \mu \mathrm{l}$ of the nuclear suspension. The final concentration of the recombinant caspases was $0.2 \mu \mathrm{g} / \mathrm{ml}$ for caspase- 3 or 0.25 units/assay in the case of caspase- 9 . Reaction mixtures were incubated for $60 \mathrm{~min}$ at $37^{\circ} \mathrm{C}$.

Electron microscopy. The suspended nuclei were fixed in $3 \%$ glutaraldehyde in $90 \mathrm{mM} \mathrm{KH} \mathrm{PO}_{4}$ buffer at $\mathrm{pH} 7.4$ for several hours. After a brief rinse in $\mathrm{KH}_{2} \mathrm{PO}_{4}$ buffer containing $7.5 \%$ sucrose, the nuclei were pelleted (1200 rpm), mixed with $20 \%$ BSA in distilled water, again pelleted and fixed overnight in the same glutaraldehyde fixative to solidify the nuclei/ BSA mixture. The solidified samples were briefly rinsed in $\mathrm{KH}_{2} \mathrm{PO}_{4}$ buffer containing $7.5 \%$ sucrose and placed for $1 \mathrm{~h}$ in 

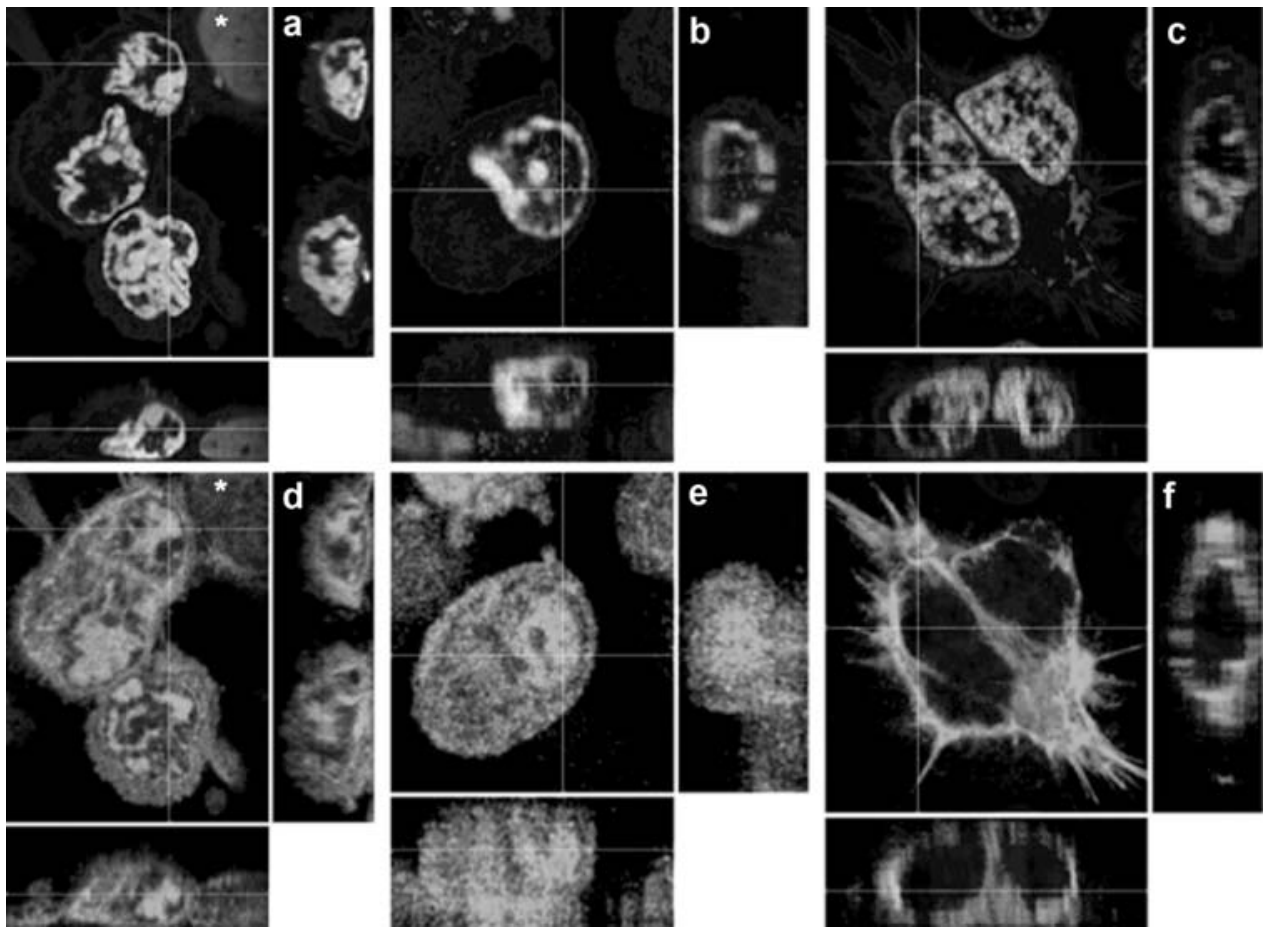

Figure 1. Nuclear morphology (a, b and c) and localization of CK18 C-terminus (d and e) and N-terminus (f) in early apoptotic MR65 (left panel) and Hela cells (middle and right panels). MR65 and Hela cells were treated with roscovitine in the presence of the caspase-6 inhibitor. After fixation cells were stained with either a polyclonal rabbit antiserum CA1 ( $\mathrm{d}$ and e), raised against the C-terminal peptide of CK18 or the monoclonal antibody M30 directed against the caspase-cleaved CK18 N-terminal fragment (f). Upper left panel, and top view, right and bottom panels, side view of a stack of confocal images. Cross hairs determine the site of cross sectioning for side viewing. Note that in these early apoptotic cells the CK18 C-terminus localizes preferably in the nucleoplasm surrounding the condensed chromatin in contrast to the non-apoptotic cell (asterisk).

$0.1 \mathrm{M} \mathrm{Na}-$ maleate buffer ( $\mathrm{pH}$ 7.4). Postfixation was performed in $2 \% \mathrm{OsO}_{4}$ in the same buffer for $1 \mathrm{~h}$, shortly rinsed with $0.1 \mathrm{M}$ Na-maleate buffer at $\mathrm{pH} 5.2$ and impregnated with $1 \%$ uranium acetate in Na-maleate buffer ( $\mathrm{pH}$ 5.2) for $15 \mathrm{~min}$ The samples were subsequently rinsed in the same buffer ( 5 min) followed by $3 \times 5$ min rinses in distilled water, routinely dehydratated in graded series of ethanol, and embedded in Epon epoxy resin. For electron microscopy ultrathin sections were counterstained with uranium acetate and lead citrate. The sections were examined with a Philips CM100 electron microscope.

\section{Results}

Subcellular localization of C-terminal CK18 peptide in (early) apoptotic cells. In order to study the localization of the CK18 C-terminal peptide more closely, apoptosis was induced using roscovitine in the presence of caspase-6-inhibitor. In this way, C-terminal cleavage of CK18 is allowed and further processing of the CK18 molecule is inhibited. Fig. 1 shows that under these conditions the $\mathrm{C}$-terminal peptide accumulates in the nucleoplasm in cells showing the typical DNA condensation characteristics of early apoptosis, whereas the N-terminal part remained exclusively outside the nucleus.

DNA binding properties of C-terminal CK18 fragment. Since the C-terminal peptide was localised in the nucleoplasm and has basic properties (a theoretical pI of 10.25), we investigated the DNA binding properties by means of the electrophoretic mobility shift assay. The C-terminal CK18 peptide was tested for binding to the negatively supercoiled pDesB25 DNA, which contained a mouse $\gamma$-satellite centromeric repeat. As a consequence of the non-B-DNA conformation which $\gamma$-satellite insert adopts under superhelical tension, this plasmid is propagated in the bacterial host in the form of supercoiled monomers and dimers (12). The electrophoretic profiles in Fig. 2A demonstrate that increasing concentrations of peptide in the binding reaction lead to decrease of both the monomeric and dimeric supercoiled (sc) DNA. High molecular weight complexes of peptide and scDNA tend to stick to surface of wells and are not entering into the agarose gel. We observed a slight reduction of the electrophoretic mobility of both forms of scDNA, that was not surprising due to low molecular weight of the C-terminal CK18 peptide. To validate the functional significance of this interaction, we tested the influence of C-terminal CK18 peptide on relaxation activity of calf thymus topoisomerase I. As depicted in Fig. 2B, the catalytic activity of topoisomerase I was increased in the presence of increasing amounts of the C-terminal CK18 peptide $(0-5 \mu \mathrm{g})$. A considerable relaxation of both the monomeric and dimeric supercoiled pDesB25 DNA with the production of a ladder of topoisomers up to totally relaxed molecules was observed in the DNA gel.

Effect of C-terminal CK18 fragment on DNA condensation and fragmentation. The band-shift and supercoiled DNA relaxation assay suggests that the 33 mer C-terminal fragment due to its affinity for naked DNA stimulates topoisomerase activity. Since it is known that topoisomerase activity contributes directly to chromatin remodeling during apoptosis 
A

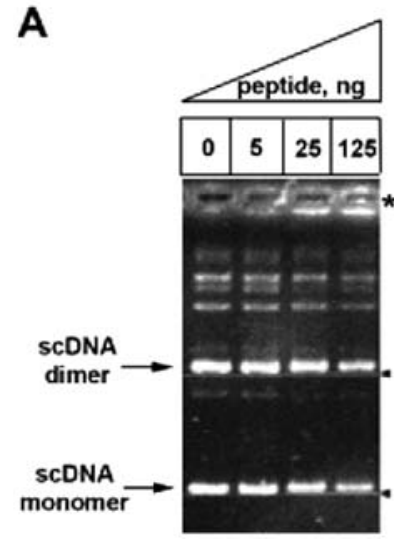

B

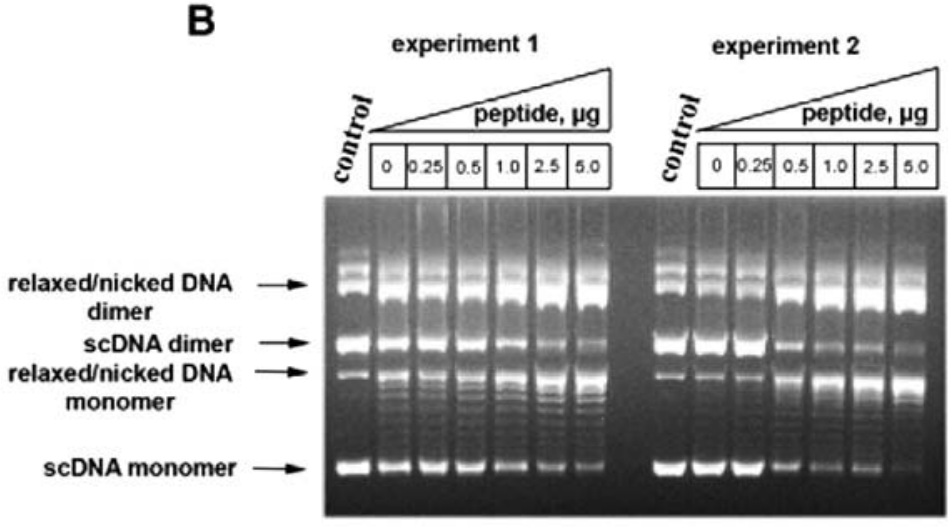

Figure 2. DNA-binding properties and stimulatory effect of CK18 C-terminal peptide on the topoisomerase I-catalysed relaxation of negatively supercoiled plasmid DNA (scDNA). (A) Increasing quantities of C-terminal CK18 peptide (0-125 ng) were incubated with $0.2 \mu \mathrm{g}$ pDesB25 DNA and the resulting complexes were subjected to agarose gel electrophoresis. Increasing quantities of peptide in the binding reaction decrease both forms of scDNA, as detected by ethidium bromide staining. The position of high molecular weight complexes of peptide and scDNA that can not migrate from the application wells is indicated by an asterisk. (B) pDesB25 DNA $(0.2 \mu \mathrm{g})$ was treated with 2 units of calf thymus topoisomerase I in the presence and absence of CK18 C-terminal peptide. The duplicate experiment is shown. Control lane represents plasmid DNA incubated in reaction buffer lacking topoisomerase I.

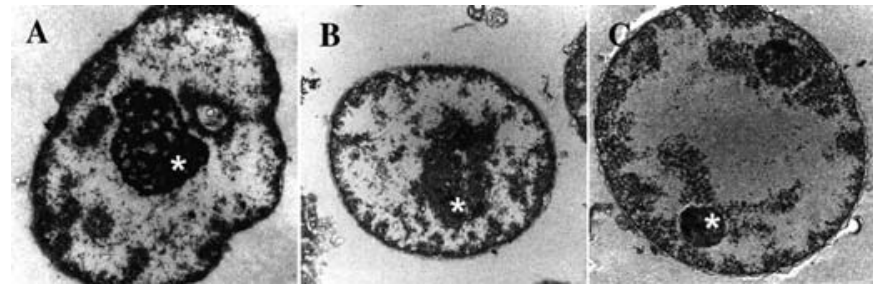

Figure 3. Nucleolar breakdown in caspase-3-treated nuclei. Electron microscopical images of isolated nuclei of Jurkat cells showing examples of increasing degeneration of the nucleolar structures ranging from a close to normal, (A) relative loosely packed (B), gradually more densely packed to a highly condensed nucleolar structure (C). The categories (A) to (C) are used to quantify the effects of the C-terminal CK18 peptide on nucleolar morphology (asterisk) during caspase treatment of isolated nuclei (summarized in Table I).

(13), we investigated whether the peptide is able to interfere with this process. To this end, nuclear preparations of Jurkat cells were treated with recombinant caspases in the presence or absence of the peptide. At the electron microscopical level it is shown that the C-terminal CK18 peptide prevents degeneration of nucleolar structures. When nuclei were incubated in absence of the 33 mer fragment a significant higher number of nuclei with highly condensed nucleolar structures was observed at the expense of nuclei showing a close to normal and loosely packed nucleolar structure (Fig. 3, Table I). When the same nuclei were treated with recombinant caspase- 3 or -9 the degeneration of nucleolar structures was more prominent, and the protective effect of co-incubation with the C-terminal CK18 peptide was less obvious. We ware unable to detect any DNA fragmentation after treatment of isolated nuclei with recombinant caspases either in the presence or absence of the C-terminal CK18 peptide (data not shown).

\section{Discussion}

The cytoskeleton is amongst the main targets of caspase proteolysis during apoptosis (7). Especially the intermediate filaments are efficiently dismantled at later stages of the process $(4,5)$. We have shown that CK18 is targeted during

Table I. Nucleolar morphology of isolated Jurkat cells treated with caspases in the presence or absence of the CK18 peptide as analyzed by electron microscopy. ${ }^{\mathrm{a}}$

\begin{tabular}{|c|c|c|c|c|c|}
\hline & Normal (\%) & Loosely packed (\%) & Densely packed (\%) & Total $(\%)$ & \\
\hline Control & $9(16.0)$ & $24(42.9)$ & $22(41.1)$ & $55(100)$ & $\mathrm{P}<0.001$ \\
\hline+ peptide & $6(11.1)$ & $42(77.8)$ & $6(11.2)$ & $54(100)$ & \\
\hline Caspase-3-treated & $4(7.1)$ & $18(32.1)$ & $34(60.7)$ & $56(100)$ & ns \\
\hline+ peptide & $6 \quad(9.0)$ & $32(47.8)$ & $29(43.2)$ & $67(100)$ & \\
\hline Caspase-9-treated & $5(6.8)$ & $8(11.0)$ & $60(82.2)$ & $73(100)$ & ns \\
\hline+ peptide & $3(4.8)$ & $10(15.9)$ & $50(79.3)$ & $63(100)$ & \\
\hline
\end{tabular}

a Statistically significant differences were calculated using the Chi-square test and expressed as p-values. ns, no statistically significant difference. 
early apoptosis resulting in the liberation of a small $33 \mathrm{mer}$ C-terminal fragment, without affecting filament organization to a great extent $(3,6)$. In this study, we investigated whether the C-terminal CK18 fragment has a functional role during the process of apoptosis.

In previous studies it was shown that intermediate filament proteins exhibit considerable in vitro affinity for nucleic acids $(12,14,15)$. Furthermore, it was shown that the liberation of the N-terminal peptide domains of vimentin by HIV-1 protease not only perturbs intermediate filament organization, but when introduced into living cells, these peptides are capable of altering chromatin distribution (11).

Since the C-terminal CK18 peptide possesses 7 amino acid residues ( 3 arginines, 3 lysines and 1 histidine) potentially involved in the interaction with nucleic acids, we tested its DNA-binding properties. We demonstrated that at low-ionic strength peptide binds to supercoiled DNA, leading to slight retardation in the electrophoretic mobility and formation of high molecular weight complexes not able to enter into the agarose gel. The fact that the C-terminal CK18 fragment shows affinity for DNA does not come as a surprise since in vivo experiments have shown that the cytokeratins of Novikoff ascites hepatoma cells can be chemically crosslinked to DNA (16). In other studies, CK8, CK18 and CK19 were not only found to be bound to nuclear DNA in human breast cancer cells in vivo, but were also observed to bind nuclear DNA in an estrogen-dependent manner, and to participate in the organization of nuclear chromatin (17). These authors suggest that the cytokeratins are authentic nuclear matrix attachment region (MAR)-binding proteins and participate in the organization and regulation of function of nuclear DNA (18).

Here we show that in the presence of the C-terminal CK18 peptide superhelical DNA is effectively relaxed by calf thymus topoisomerase I. The effect of CK18 C-terminal peptide is similar to spermidine $(19,20)$ and a related compound, radioprotector WR-33278 (21), which strongly bind to DNA and facilitate relaxation of supercoiled DNA by topoisomerase I. However, electrostatic interactions alone between positively charged amino groups and DNA are not enough to stimulate activity of topoisomerase I, because poly-L-arginine even at high weight ratio to DNA has no effect (19). It seems that the spacing between amino groups as well as conformation of DNA interacting molecule are more important for stimulation of topoisomerase I reactivity. Both spermidine and WR-33278 compound are linear, symmetrical molecules bearing amino groups on their ends. The 33mer C-terminal fragment contains two nearly perfect symmetrical motifs KTTTRR and KVLRH containing 6 out of 7 positively charged at neutral $\mathrm{pH}$ residues potentially involved in binding to DNA. This structural similarity prompted us to speculate that the mechanism of topoisomerase I activation by CK 18 C-terminal peptide and polyamines is related. Eukaryotic topoisomerases bind preferentially and specifically to helix-helix juxtapositions on negatively supercoiled DNA molecules (22). As the two interacting DNA segments in the points of DNA crossovers are repelling, it is tentative to speculate that electrostatic shielding of phosphates by bivalent, symmetrical molecules minimize the repulsion, stabilize the juxtapositions, facilitating the binding of topoisomerases and enhancing in this way their supercoil-relaxing activity. The competition for binding to the same DNA structure can be a limiting factor, however, such interference can be excluded because topoisomerase I (23) and II (24) bind to the minor groove of DNA, whereas spermidine (25) prefers the major groove. In this respect, it is worthwhile to mention that stimulatory effect of vimentin and GFAP on activity of topoisomerases is highly likely mediated via binding of these oligomeric proteins to the points of DNA crossovers (26).

Physiological role of nuclear localization of the C-terminal CK18 peptide during apoptosis. We have demonstrated that the C-terminal CK18 peptide can participate in the protection of nucleolar organization during the early stages of apoptosis. The liberated peptide has basic properties and it has been shown previously that basic proteins can affect chromatin condensation directly $(27,28)$. However, relatively high levels of peptide are needed in comparison to full-length basic nuclear proteins (29).

In this respect, it is more likely that the C-terminal CK18 fragment plays a specific role during apoptosis in modulating topoisomerase I activity by cooperative binding to supercoiled DNA and changing its conformation or by physical interaction with the enzyme. Topoisomerase I is an abundant nuclear protein (30) that diffuses between nucleoplasm and nucleolus and accumulates in the fibrillar centers of the nucleolus (31) where it assists in rDNA transcription (32). Topoisomerase I is also involved in apoptosis (33) and although it is a substrate of caspases, the cleavage fragments remain in proximity of the chromatin and retain the ability to bind to and cleave DNA (34).

The toxic effect of the inhibitors of cyclin-dependent kinases (CDKs) is thought to be mediated via fragmentation and condensation of nucleolus and inhibition of proper maturation of rRNA (35). The later process is not only strongly sensitive to roscovitine treatment (36), but also depends on topoisomerase I and its nucleolar interaction partner p14ARF (37). At the EM level the presence of the peptide seemed to ameliorate the degenerative effects of incubation at $37^{\circ} \mathrm{C}$ on the structure of the nucleolus, as deduced from a shift in nucleolar morphology towards a more normal appearance. This finding supports an inhibitory role of the C-terminal peptide in nucleolar breakdown and fragmentation possibly via modulation of topoisomerase I activity.

Based on our observations, we speculate that translocated C-terminal CK18 peptide assists topoisomerase I in the adequate performance of nucleolar processes during the initial phase of apoptosis and indirectly supports protein biosynthesis via regulation of rDNA transcription and rRNA processing.

\section{Acknowledgements}

We gratefully acknowledge gift of the anti-C terminal K18 antibody (E.B. Lane, University of Dundee, UK). The authors acknowledge the Dutch Science Foundation (NWO; project no. 901-28-134) for the financial support for the vital imaging digital microscopy system and the Imaris/Huygens software running on a Silicon Graphics workstation. 


\section{References}

1. Nicholson DW: Caspase structure, proteolytic substrates, and function during apoptotic cell death. Cell Death Differ 6: 1028-1042, 1999.

2. Caulin C, Salvesen GS and Oshima RG: Caspase cleavage of keratin 18 and reorganization of intermediate filaments during epithelial cell apoptosis. J Cell Biol 138: 1379-1394, 1997.

3. Schutte B, Henfling M, Kölgen W, et al: Keratin 8/18 breakdown and reorganization during apoptosis. Exp Cell Res 297: 11-26, 2004.

4. Byun Y, Chen F, Chang R, Trivedi M, Green KJ and Cryns VL: Caspase cleavage of vimentin disrupts intermediate filaments and promotes apoptosis. Cell Death Differ 8: 443-450, 2001.

5. Chen F, Chang R, Trivedi M, Capetanaki Y and Cryns VL: Caspase proteolysis of desmin produces a dominant-negative inhibitor of intermediate filaments and promotes apoptosis. J Biol Chem 278: 6848-6853, 2003.

6. Leers MP, Kölgen W, Björklund V, et al: Immunocytochemical detection and mapping of a cytokeratin 18 neo-epitope exposed during early apoptosis. J Pathol 187: 567-572, 1999

7. Marceau N, Schutte B, Gilbert S, et al: Dual roles of intermediate filaments in apoptosis. Exp Cell Res (Special Issue Intermediate Filaments) 313: 2265-2281, 2007.

8. Broers JLV, Bronnenberg NM, Kuijpers HJ, Schutte B, Hutchison CJ and Ramaekers FCS: Partial cleavage of A-type lamins concurs with their total disintegration from the nuclear lamina during apoptosis. Eur J Cell Biol 81: 677-691, 2002.

9. Ruchaud S, Korfali N, Villa P, Kottke TJ, Dingwall C, Kaufmann SH and Earnshaw WC: Caspase-6 gene disruption reveals a requirement for lamin A cleavage in apoptotic chromatin condensation. EMBO J 21: 1967-1977, 2002.

10. Clem RJ, Sheu T-T, Richter BWM, He W-W, Thornberry NA, Duckett CS and Hardwick JM: c-IAP1 is cleaved by caspases to produce a proapoptotic C-terminal fragment. J Biol Chem 276: 7602-7608, 2001.

11. Shoeman RL, Huttermann C, Hartig R and Traub P: Aminoterminal polypeptides of vimentin are responsible for the changes in nuclear architecture associated with human immunodeficiency virus type 1 protease activity in tissue culture cells. Mol Biol Cell 12: 143-154, 2001.

12. Li G, Tolstonog GV, Sabasch M and Traub P: Interaction in vitro of type III intermediate filament proteins with supercoiled plasmid DNA and modulation of eukaryotic DNA topoisomerase I and II activities. DNA Cell Biol 21: 743-769, 2002.

13. Widlak P, Li P, Wang X and Garrard WT: Cleavage preferences of the apoptotic endonuclease DFF40 (Caspase-activated DNase or nuclease) on naked DNA and chromatin substrates. J Bio Chem 275: 8226-8232, 2000.

14. Kuhn S, Vorgias CE and Traub P: Interaction in vitro of nonepithelial intermediate filament proteins with supercoiled plasmid DNA. J Cell Sci 87: 543-554, 1987.

15. Hartig R, Shoeman R, Janetzko A, Tolstonog G and Traub P: DNA-mediated transport of the intermediate filament protein vimentin into the nucleus of cultured cells. J Cell Sci 111: 3573-3584, 1998 .

16. Olinski R, Wedrychowski A, Schmidt WN, Briggs RC and Hnilica LS: In vivo DNA-protein cross-linking by cis- and trans-diamminedichloroplatinum(II). Cancer Res 47: 201-205, 1987.

17. Spencer VA, Coutts AS, Samuel SK, Murphy LC and Davie JR: Estrogen regulates the association of intermediate filament proteins with nuclear DNA in human breast cancer cells. J Biol Chem 273: 29093-29097, 1998.

18. Spencer VA, Samuel SK and Davie JR: Nuclear matrix proteins associated with DNA in situ in hormone-dependent and hormone-independent human breast cancer cell lines. Cancer Res 60: 288-292, 2000.
19. Akama K, Kondo M, Sato H and Nakano M: Transition protein 4 from boar late spermatid nuclei is a topological factor that stimulates DNA-relaxing activity of topoisomerase I. FEBS Lett 442: 189-192, 1999.

20. Srivenugopal KS and Morris DR: Differential modulation by spermidine of reactions catalyzed by type 1 prokaryotic and eukaryotic topoisomerases. Biochemistry 24: 4766-4771, 1985.

21. Holwitt EA, Koda E and Swenberg CE: Enhancement of topoisomerase I-mediated unwinding of supercoiled DNA by the radioprotector WR-33278. Radiat Res 124: 107-109, 1990.

22. Zechiedrich EL and Osheroff N: Eukaryotic topoisomerases recognize nucleic acid topology by preferentially interacting with DNA crossovers. EMBO J 9: 4555-4562, 1990.

23. Chen AY, Yu C, Gatto B and Liu LF: DNA minor groovebinding ligands: a different class of mammalian DNA topoisomerase I inhibitors. Proc Natl Acad Sci USA 90: 8131-8135, 1993.

24. Bell A, Kittler L, Lober G and Zimmer C: DNA binding properties of minor groove binders and their influence on the topoisomerase II cleavage reaction. J Mol Recognit 10: 245-255, 1997.

25. Deng H, Bloomfield VA, Benevides JM and Thomas GJ Jr: Structural basis of polyamine-DNA recognition: spermidine and spermine interactions with genomic B-DNAs of different GC content probed by Raman spectroscopy. Nucleic Acids Res 28: 3379-3385, 2000

26. Li G, Tolstonog GV, Sabasch M and Traub P: Type III intermediate filament proteins interact with four-way junction DNA and facilitate its cleavage by the junction-resolving enzyme T7 endonuclease I. DNA Cell Biol 22: 261-291, 2003.

27. Balhorn R, Brewer L and Corzett M: DNA condensation by protamine and arginine-rich peptides: analysis of toroid stability using single DNA molecules. Mol Reprod Dev 56 (Suppl. 2): S230-S234, 2000

28. Keller M, Tagawa T, Preuss M and Miller AD: Biophysical characterization of the DNA binding and condensing properties of adenoviral core peptide mu. Biochemistry 41: 652-659, 2002.

29. Brewer L, Corzett M and Balhorn R: Condensation of DNA by spermatid basic nuclear proteins. J Biol Chem 277: 38895-38900, 2002.

30. Leppard JB and Champoux JJ: Human DNA topoisomerase I: relaxation, roles, and damage control. Chromosoma 114: 75-85, 2005.

31. Christensen MO, Krokowski RM, Barthelmes HU, Hock R Boege F and Mielke C: Distinct effects of topoisomerase I and RNA polymerase I inhibitors suggest a dual mechanism of nucleolar/nucleoplasmic partitioning of topoisomerase I. J Biol Chem 279: 21873-21882, 2004

32. Zhang H, Wang JC and Liu LF: Involvement of DNA topoisomerase I in transcription of human ribosomal RNA genes. Proc Natl Acad Sci USA 85: 1060-1064, 1988.

33. Soe K, Rockstroh A, Schache P and Grosse F: The human topoisomerase I damage response plays a role in apoptosis. DNA Repair 3: 387-393, 2004.

34. Samejima K, Svingen PA, Basi GS, et al: Caspase-mediated cleavage of DNA topoisomerase I at unconventional sites during apoptosis. J Biol Chem 274: 4335-4340, 1999.

35. Sirri V, Hernandez-Verdun D and Roussel P: Cyclin-dependent kinases govern formation and maintenance of the nucleolus. J Cell Biol 156: 969-981, 2002.

36. Schlosser I, Holzel M, Murnseer M, Burtscher H, Weidle UH and Eick D: A role for c-Myc in the regulation of ribosomal RNA processing. Nucleic Acids Res 31: 6148-6156, 2003.

37. Ayrault O, Andrique L, Larsen CJ and Seite P: Human Arf tumor suppressor specifically interacts with chromatin containing the promoter of rRNA genes. Oncogene 23: 8097-8104, 2004. 